Law, Culture and the Humanities

\section{Animal Norms: An Investigation of Normativity in the Non-Human Social World}

(C) The Author(s) 2018 Article reuse guidelines: sagepub.com/journals-permissions DOI: I0.II77/I743872II8800008 journals.sagepub.com/home/lch

(S)AGE

\author{
Giuseppe Lorini \\ Università degli Studi di Cagliari, Cagliari, Italy
}

\begin{abstract}
A human being is not only a social and teleological animal, she/he is also a nomic animal, a creature that can act in light of rules. Starting from this new image of humankind, the author extends the investigation of normativity to other members of the animal kingdom, posing the question of whether other nomic animals exist outside the human species. Generally, the consensus tends toward the idea that non-human animals are incapable of acting in light of rules, as if this capacity were a specific characteristic of humanity excluded to all other species. The author instead assembles three impactful answers that counter this consensus, posited respectively by a legal expert, an ethologist, and a philosopher, responses that may pave the way for a new field of research: the ethology of normativity. In conclusion, the author points out how these new inquiries advance novel ideas of normativity that deserve investigating further, such as a "normativity without language," and a "normativity without norms."
\end{abstract}

\title{
Keywords
}

normativity, animal norms, nomic capacity, nomic animal, ethology of normativity, legal ethology, naïve normativity

\section{Introduction: Man as a Nomic Animal}

We all live immersed in a "nomosphere," a world of norms of which we are often unaware. ${ }^{1}$ As Norberto Bobbio writes, "[w]e believe that we are free, but in reality we are enveloped

1. See David Delaney, The Spatial, the Legal and the Pragmatics of World-Making. Nomospheric Investigations (Abingdon: Routledge, 2010).

\section{Corresponding author:}

Giuseppe Lorini, Department of Law, Università degli Studi di Cagliari, Viale Sant'lgnazio 17, Cagliari, 09|23, Italy.

Email: lorini@unica.it 
in a dense network of rules."2 This is one of Émile Durkheim's great insights: we believe that we are acting freely, but we have to face what he calls "social facts," namely, those social realities that consist of ways of acting, thinking and feeling, outside of the individual, which are capable of exerting over the individual an external constraint. ${ }^{3}$ According to Durkheim, we all live enmeshed in a form of social normativity that is objective inasmuch as it is ontologically independent of us. When we perform our duties as siblings, spouses, or citizens, we are carrying out duties that have not been created by us, but which have rather been defined outside of us, and which we have received through education. ${ }^{4}$

A human being is therefore not only a social animal or a teleological animal, it is also a "nomic animal," a "rule-following animal." This new image of humankind has been sketched out by at least four philosophers who scrutinized our economic, social, and political realities at length over the past seventy years, namely Wilfrid Sellars, Friedrich August von Hayek, Robert Nozick, and John Searle. ${ }^{5}$

In his essay "Language, Rules and Behavior," Wilfrid Sellars states that to speak of a human as a rational animal is nothing more than describing a human as "a creature of rules." With a hint of humour, Sellars adds that "[w]hen God created Adam, he whispered in his ear, 'In all contexts of action you will recognise rules, if only the rule to grope for rules to recognise. When you cease to recognise rules, you will walk on four feet." 6

In his book Law, Legislation and Liberty, Friedrich August von Hayek describes the human not only as an animal that acts according to its own "Zweckrationalität" (to use Max Weber's terminology), but also one that acts according to its own rules: "[M]an is as much a rule-following animal as a purpose-seeking one."7

We find a similar image of humanity in Robert Nozick. In Nozick's opinion, humans are not only animals that have the ability to act in a cooperative and teleological way, but they are also endowed with what we could call a "nomic capacity," namely the capacity to have one's behaviors guided by norms. ${ }^{8}$

2. Norberto Bobbio, La teoria della norma giuridica (Torino: Giappichelli, 1958), p. 3.

3. Émile Durkheim, Les règles de la méthode sociologique (Paris: Félix Alcan, 1895), p. 6.

4. This fruitful concept by Durkheim was subsequently developed in different directions in the field of social psychology, especially by Erving Goffman in the United States and Serge Moscovici in France. For more on normativity as a central feature of sociality, see J.K. Swindler, "Normativity: From Individual to Collective," Journal of Social Philosophy 39(1) (2008), 116-30.

5. See Giuseppe Lorini and Francesco Marrosu, "How Individual Habits Fit/Unfit Social Norms: From the Historical Perspective to a Neurobiological Repositioning of an Unresolved Problem," Frontiers in Sociology 3 (2018), 14.

6. Wilfrid Sellars, "Language, Rules and Behavior," in Jeffrey F. Sicha (ed.), Pure Pragmatics and Possible Worlds. The Early Essays of Wilfrid Sellars (Atascadero, CA: Ridgeview, 1980), p. 138. (First edition: 1949.)

7. Friedrich August von Hayek, Law, Legislation and Liberty: A New Statement of the Liberal Principles of Justice and Political Economy (London: Routledge \& Kegan Paul, 1982), p. 11.

8. Robert Nozick, Invariances. The Structure of the Objective World (Cambridge, MA: Harvard University Press, 2001), p. 270. With regard to this image of man, it is important to emphasize that while Sellars and Nozick seem to limit the notion of nomic animal to human beings, Hayek also extends it to non-human animals. In particular, Hayek (in his essay "Notes on the Evolution of Systems of Rules of Conduct," in Bruce Caldwell (ed.), Collected Papers of F.A. 
This nomic capacity is also highlighted by John Searle when he describes humans as animals who possess the "ability to follow a set of rules, procedures or practices"9 because of their biological structure. ${ }^{10}$ According to Searle, this capacity is at the root of human civilization itself. Without it, the very possibility of coexistence between humans would be in doubt, and certainly our complex everyday reality composed of states, universities, parliaments, contracts, weddings, conferences, banknotes, university lectures, and football matches could not exist. ${ }^{11}$

But what does this ability consist of exactly? As we have seen, Hayek and Searle in particular use the expression "to follow rules" to describe this human ability, but it would be more correct to say that humanity is not only able to follow rules, in other words to "act in accordance with rules," but is capable of "acting in light of rules," more generally.

von Hayek. Volume 15: The Market and the Other Orders (Chicago, IL: The University of Chicago Press, 2014), p. 279 (first edition: 1967)) examines the issue of the nomic behavior of non-human animals, when he investigates the role of the rules of conduct in human and animal societies: "A society of animals or men is always a number of individuals observing such common rules of conduct as, in the circumstances in which they live, will produce an order of actions." According to Hayek ("Notes on the Evolution," p. 281), the most obvious cases of animal nomic behavior consist of "spatial models" of action adopted while on the move or during defense or hunting activities carried out by groups: "The arrow formation of migrating wild geese, the defensive ring of the buffaloes, or the manner in which lionesses drive the prey towards the male for the kill, are simple instances in which presumably it is not an awareness of the overall pattern by the individual but some rules of how to respond to the immediate environment which co-ordinate the actions of the several individuals."

9. More recently, this image of humanity was assumed in the research conducted by the American psychologist Michael Tomasello on the cultural origins of human cognition. See Michael Tomasello, A Natural History of Human Thinking (Cambridge, MA: Harvard University Press, 2014).

10. John R. Searle, "Social Ontology and Political Power," in Frederick F. Schmitt (ed.), Socializing Metaphysics: The Nature of Social Reality (Oxford: Rowman \& Littlefield, 2003), p. 200.

11. John Searle hypothesizes that there are biological prerequisites for this human capacity. But what are they? Over 30 years ago Jane Goodall (in her essay "Order without Law," in Margaret Gruter and Paul Bohannan (eds.), Law, Biology \& Culture: The Evolution of Law (San Diego, CA: Ross-Erickson, 1983), pp. 50-62) encouraged the study of the biological basis of human legal behavior, and in parallel to this Margaret Gruter (in her essay "Ostracism as a Social and Biological Phenomenon: An Introduction," Ethology and Sociobiology 7 (1986), 149-58) emphasized the importance of the fact that neurosciences began to deal with questions that were later only covered by the normative sciences. The first contributions to this new investigation have come from Antonio R. Damasio, Decartes' Error. Emotion, Reason, and Human Brain (New York: Avon Books, 1994); Patricia S. Churchland, Braintrust: What neuroscience tells us about morality (Princeton, NJ: Princeton University Press, 2011); Jaak Panksepp, Affective Neuroscience: The Foundations of Human and Animal Emotions (Oxford: Oxford University Press, 1998); Naotaka Fujii and Atsushi Iriki, "Social Rules and Body Scheme," in Frans B.M. de Waal and Pier Francesco Ferrari (eds.), The Primate Mind: Built to Connect with Other Minds (Cambridge, MA: Harvard University Press, 2012), pp. 48-64; Jaak Panksepp and Lucy Biven, The Archaeology of Mind: Neuroevolutionary Origins of Human Emotion (New York: W.W. Norton \& Company, 2012). 
This is certainly a more accurate description of nomic capacity. Amedeo Giovanni Conte has called the phenomenon of acting in light of norms "nomotropism."12 The term "nomotropism" derives from the two Greek words nomos (norm) and trépo (turning). The origin of the ingenious term is quite evident. Just as in the case of phototropism the sunflower orients itself according to the light of the sun, in the case of nomotropism the agents orient themselves according to norms. ${ }^{13}$

As Conte points out, nomic behavior is not necessarily behavior that conforms to norms. Indeed, there are nomotropic behaviors that do not consist of "following rules." It is indeed possible to act in light of rules, that is to orient one's own actions according to rules, without acting in accordance with these rules. This phenomenon has already been studied by Max Weber, who writes that a thief, when acting secretly with the intent to steal, orients his behavior according to the very rules that he is breaking. ${ }^{14}$ One strange case of nomic behavior that does not consist of compliance with norms is described by Heinrich Böll in his book Irisches Tagebuch. In a story about life in Irish pubs during the summer period, Böll describes the strange actions of a landlord who fixed the hands of the clock on the wall of his pub with screws to always show the time 10:30. He did this at the start of summer, and the hands remained frozen at that hour for the entire season. The purpose of this bizarre act is explained by the legal closing-time for countryside pubs of 22:30. Thus we realize that the publican's nomic behavior does not so much consist of fulfilling the legal requirement, but is instead to circumvent the rules and facilitate the violation. The pub landlord is acting in light of a rule that he is determined to break rather than follow. ${ }^{15}$

\section{Are There Non-Human Nomic Animals?}

After these general reflections on mankind as a nomic animal, I will now extend the investigation of nomic behavior and nomic capacity to other members of the animal kingdom, posing the following question: assuming humans are indeed nomic by nature, are they the only animals capable of acting in light of rules? In other words: do other nomic animals exist outside the human species?

Generally, the consensus tends toward the idea that non-human animals are incapable (but also unable to become capable) of acting in light of rules, as if nomic capacity were a specific characteristic of humanity excluded to all other species. ${ }^{16}$

12. Amedeo Giovanni Conte, "Nomotropismo: agire in funzione di regole," Sociologia del diritto 27(1) (2000), 1-27.

13. Obviously, teleological behavior and nomic behavior are not mutually incompatible. It is also possible to act teleologically in light of rules. See Giuseppe Lorini, "La norma come strumento," in Alberto Contu (ed.), Questione sarda e dintorni. Liber amicorum per Gianfranco Contu (Cagliari: Condaghes, 2012), pp. 183-7.

14. Max Weber, "Über einige Kategorien der verstehenden Soziologie," Logos. Internationale Zeitschrift für Philosophie der Kultur 4 (1913), pp. 253-93.

15. Heinrich Böll, Irisches Tagebuch (München: Deutscher Taschenbuch Verlag, 2000), p. 46.

16. I would like to specify that, in this article, I will concentrate on normativity that we could describe as "deontic" to distinguish it from "epistemic" normativity. For more on epistemic normativity in non-human animals, see two essays by Laura Danón: "Normatividad doxástica 
This thesis was expressed (in relation to chimpanzees, specifically) by the famous ethologist Jane Goodall in her essay “Order without Law” published in 1983. After studying the behavior of these apes at the Gombe National Park in Tanzania, in her essay she reaches the conclusion that, in the case of chimpanzees, while there is undoubtedly a "social order" (indeed, she describes many kinds of behavioral patterns that are widespread among the chimpanzees in the Park), there is no parallel "law" or set of "laws." According to Goodall, there is an order in chimpanzee society, but this order "is maintained without 'laws' in the human sense of the term." 17 It is an order founded on the ranking of the various individuals and on the "might is right" principle, without it being possible to talk about actual social sanctions imposed on the member that has violated the social codes. ${ }^{18}$

The same thesis was recently formulated in relation to non-human primates by Keith Jensen, Amrisha Vaish, and Marco F.H. Schmidt, who state that, at present, there is no evidence that primates have anything resembling norms. They claim that primates "do follow sanction-based 'rules' in their groups, such as 'subordinate individuals do not take food away from dominants,' but there is nothing binding or general about these. Individual learning and fear of retaliation is sufficient. Primates have been said to have a 'respect for possession' in which dominant individuals will not take food from subordinates (Kummer and Cords 1991), but this is, of course, not a normative notion, and a rather crude analogy to the normative institution of ownership in humans." 19,20

en animales no humanos," Analítica 5(5) (2011), 9-28, and "Pushmi-pullyu Representations and Mindreading in Chimpanzees," Studia Philosophica Estonica 9(1) (2016), 208-36. Investigating animal capacity for prediction, Danón ("Pushmi-pullyu," p. 210) hypothesizes the epistemic capacity of animals for making predictions on the basis of behavioral rules alongside the mind-reading capacity hypothesis: "When some animals predict the behavior of others in a way which suggests they are mindreading, it is always possible to give an alternative explanation, according to which they are exclusively basing their predictions on 'behavioral rules' that associate the available behavioral/environmental cues with the consecutive behavior of the agent."

17. Goodall, "Order without Law," p. 61.

18. In fact, despite Goodall's argument, several elements emerge from reading her essay that appear to suggest the existence of social norms in chimpanzee society. These norms are transmitted by adults, especially mothers, to infants through example and punishment.

19. Keith Jensen, Amrisha Vaish and Marco F.H. Schmidt, "The Emergence of Human Prosociality: Aligning with Others through Feelings, Concerns, and Norms," Frontiers in Psychology 5 (2014), 822. However, Jensen, Vaish and Schmidt's thesis is not devoid of inconsistencies. Although they argue that there is no evidence of the existence of norms in primate societies, they claim that primates follow certain sanction-based rules and that an important element for engaging in behavior that is deferential with respect to the rules is the fear of retaliation. After all, even the thesis of the non-normativity of the institution of ownership in non-human societies has yet to be demonstrated. For a recent survey on the various forms of possession and property in non-human primate societies, see Sarah F. Brosnan, "Property in non-human primates," New Directions for Child \& Adolescent Development 132 (2011), 9-22.

20. See Hans Kummer and Marina Cords, "Cues of ownership in long-tailed macaques, Macaca fascicularis," Animal Behaviour 42(4) (1991), 529-49. 
The lack of convincing evidence that non-human primates understand normativity or develop normative attitudes toward their conspecifics' actions is also reaffirmed by Marco F.H. Schmidt and Hannes Rakoczy in the essay "On the uniqueness of human normative attitudes." According to them, human beings are the only normative species. Unlike non-human animals, "[h] umans also 'ought' to do certain things, such as standing in line at the grocery store, accepting Euros as currency in some countries, or refraining from hurting one another. It is undeniable that humans (understand themselves to) have rights and obligations, and create their own 'laws' - social norms - to regulate and give meaning to socio-cultural life."21

John Searle also agrees that humans are the only animals that can act "because of the rule." Indeed, he argues that in the absence of a language or some form of symbolism underlying certain behavioral dispositions that generate behavioral regularity, there can be no recognition of obligations or duties. In particular, Searle distinguishes between a simple disposition not to cross the line, and recognition of the fact that one is under obligation not to cross the line. In Searle's view, if we train a dog not to leave the garden with punishments and rewards, we are modifying its disposition. There is no space for obligation or duty here. ${ }^{22}$

The distinction between mere dispositions and fully fledged normative and institutional structures is exemplified by the difference between the fact that a tribe has a recognized leader whereas a pack of wolves has an alpha male: a leader has a deontic status represented by and created by language, whereas the alpha male wolf is respected just because of his physical strength, and in the latter case there is no deontology given. ${ }^{23}$

Moreover, Searle claims that to recognize an obligation requires the concept itself of "obligation," which is the only theoretical tool that allows us to represent something as an obligation. ${ }^{24}$ While the word "obligation" is not in itself necessary, there must be a "conceptual apparatus" rich enough to represent the normative and institutional structure, namely what Searle calls "deontology." 25

21. Marco F.H. Schmidt and Hannes Rakoczy, "On the uniqueness of human normative attitudes," in Kurt Bayertz and Neil Roughley (eds.), The Normative Animal? On the Anthropological Significance of Social, Moral and Linguistic Norms (Oxford: Oxford University Press, forthcoming).

22. John R. Searle, Making the Social World: The Structure of Human Civilization (Oxford: Oxford University Press, 2010), p. 95.

23. Op. cit., p. 95.

24. Op. cit., pp. 95-6.

25. Interesting questions arise at the intersection between the ethological study of normativity and social ontology: are constitutive rules possible in animal societies? Can non-human animals ascribe status-functions to things? A negative response to these two questions seems to come from Hannes Rakoczy, "Comparative Metaphysics: the Development of Representing Natural and Normative Regularities in Human and Non-Human Primates," Phenomenology and the Cognitive Science 14(4) (2015), 683-97. See also George P. Fletcher, "Law," in Barry Smith (ed.), John Searle (Cambridge: Cambridge University Press, 2003), pp. 85-101; and Hannes Rakoczy and Michael Tomasello, "The ontogeny of social ontology: Steps to shared intentionality and status functions," in S.L. Tsohatzidis (ed.), Intentional acts and institutional facts: Essays on John Searle's social ontology (Dordrecht: Springer, 2007), pp. 113-37. But I believe that research on this question is still ongoing. 
But is it really true that non-human animals cannot act in light of rules and duties? Furthermore, is it true that language is a pre-condition of nomic action and normativity?

An affirmative answer to the question of whether there are any nomic non-human species in the animal kingdom can be found in different studies recently conducted by ethologists, jurists, and philosophers on the hypothetical moral, legal, and nomic actions of non-human animals. Although this essay will span different studies on the morality and also the legal framework of animal conduct, I would nevertheless like to focus specifically on the question of the normativity of animal behavior, which is probably a pre-condition of moral and legal behavior that is often left in the background. ${ }^{26}$ I will now present a reconstruction of the three main positive answers to the question of whether non-human animals can act in light of rules, put forward by a legal expert (Rodolfo Sacco), an ethologist (Frans de Waal), and a philosopher (Kristin Andrews) respectively. ${ }^{27}$

\section{III. “Mute Normativity” in Non-Human Animals (Rodolfo Sacco)}

A first affirmative response to the question of whether there are non-human animals capable of acting in light of rules comes from the theory of "diritto muto" (mute law) proposed by the Italian jurist Rodolfo Sacco. ${ }^{28}$ Imagining the dawn of law in its prehistory, Sacco reflects on a form of law that characterizes the societies of non-human animals and pre-linguistic humans. Within this context he sketches a portrait of "mute" legal

26. For an exception, see Sarah Vincent, Rebecca Ring and Kristin Andrews, "Normative Practices of Other Animals," in Aaron Zimmerman, Karen Jones and Mark Timmons (eds.), The Routledge Handbook of Moral Epistemology (London: Routledge, forthcoming). One phenomenon that is certainly relevant for investigating the existence of norms in animal societies is that of the "conformity" of the individual's behavior to that of the group. On this topic, see Erica van de Waal, Christèle Borgeaud and Andrew Whiten, "Potent Social Learning and Conformity Shape a Wild Primate's Foraging Decisions," Science 340(6131) (2013), 483-5; Carel P. van Schaik, “Animal culture: Chimpanzee conformity?," Current Biology 22 (2012), 922-6; and C.P. van Schaik and Judith Burkart, "The Evolution of Human Normativity: The Role of Prosociality and Conformity," unpublished paper, 2016. [https://www.aim.uzh. ch/dam/jcr:fd03d413-5d98-4feb-85ea-b69f571e9fb2/van\%20Schaik\%20\&\%20Burkartfinal-2015.pdf] (accessed August 21, 2018).

27. Alongside these three recent researches, it is worth remembering the work of the Italian philosopher Cesare Goretti who about 90 years ago already questioned the possibility of animals being able to act in light of norms in his pioneering essay "L'animale quale soggetto di diritto" (The Animal as Legal Subject), Rivista di filosofia 19 (1928), 348-69. Here Goretti assumes that non-human animals may be endowed with an "auroral legal consciousness" and may therefore have in a certain sense, an albeit primitive perception of legal normativity. According to Goretti, it cannot be ruled out that a pet (for example, a guard dog) has an obscure sense of ownership or obligation.

28. See, in particular, Rodolfo Sacco, "Mute Law," The American Journal of Comparative Law 43(3) (1995), 455-67, and R. Sacco, Il diritto muto. Neuroscienze, conoscenza tacita, valori condivisi (Bologna: Il Mulino, 2015). 
normativity characteristic of non-linguistic social contexts, which manifests without linguistic phenomena.

Law provides means to prevent and solve conflicts throughout society. Wherever we find a society we will find law. This holds true in human societies, as well as in advanced animal societies. Lions, wild dogs and many other carnivorous mammals "mark" their territory and obtain from their counterparts, i.e., from other members of their species, observance of their exclusive rights. ${ }^{29}$

What is true of the societies of mammals that came before, and primates in particular, is obviously also true for humanity. As Sacco writes, "[w] hen the Homo Habilis produced the first pebble tools, his law could not be too different from that of the primates which immediately preceded him. Those pebble tools created issues of property, extending through time, of chattels: the weapon or the rock (flint stone, quartz, oxydian), valuable insofar as rare, to make the weapon. Possession probably solved the most common problems." 30

Sacco outlines a society of pre-linguistic animals in which relationships are colored by legal and normative qualifications. Mute legal acts (for example, marking territory or courtship) define relationships from a legal standpoint and give rise to duties: "[r]ules observed by the animal itself protect the relationship between male and female, often preceded by courtship, and the duties incumbent on the parents with respect to their offspring." 31

Clearly, the hypothesis presupposed by this image of law is that the pre-linguistic human and certain non-human social animals are able to act in light of rules, and are therefore endowed with nomic capacity. Moreover, the idea of rule and duty is an essential element of this outline of mute law, in which Sacco stresses fidelity to rules and the validity of rules as a way of reconstructing what we could describe (using a term by John Searle) as a sort of "animal deontology." Sacco would later say incisively that law exhausts itself in its rules. The validity of a rule lies in the compliance of those affected by it, and therefore in the fact that people behave obediently and submissively toward it. ${ }^{32}$ As Sacco writes: "Ceremonies and acts constituted legal acts. Adherence to the rule implied its existence and validity (manifested by the spontaneous conduct of the members of the group)." 33 In this law, compliance with the rule is guaranteed by self-protection, and selfprotection is in turn strengthened by the very biology of the animal. Glands and hormones come into play, multiplying the strength of the animal that is unfairly under attack. We find ourselves faced with a sort of legal normativity made flesh.

It is a very particular kind of law, however, that is often not affected by ceremonial legal acts, and the existence of the legal relationship coincides with the enactment of the relationship itself.

$[\mathrm{P}]$ ossession constituted the exercise of legal power over the chattel, acquiescence implied recognition of the other's rights, performance implied obligation. The dichotomy between law
29. Sacco, "Mute Law," 459.
30. Op. cit., 459.
31. Op. cit., 459.
32. Sacco, Il diritto muto, p. 76.
33. Sacco, "Mute Law," 460. 
and enforcement did not exist. The acts that were performed were legal, in other words, the right exercised was legal, the duty absolved was legal, the act acquiesced by others was legal. ${ }^{34}$

A good example of Sacco's idea that acquiescence implies law can be found in de Waal's book Primates and Philosophers, in which the author describes the behavior of capuchin monkeys (Cebus apella). ${ }^{35}$ These monkeys are usually interested in the food of others, and every now and again they seem ready to share it, at times even offering some to a companion. De Waal emphasizes the fact that this sharing is generally passive, inasmuch as usually the transaction happens when another individual from the group extends their hand to take the food, and they are allowed to do so.

Sacco also makes an interesting observation concerning the category of "norms" and the word "norm." He reflects on the relationship between the norm and its factual correlation, namely behavior compliant with the norm:

\begin{abstract}
Speaking jurists have given names to rules, subjective rights and legal duties. They were not so generous with behaviours conforming to rules, exercise of subjective rights, and performance of duties. They define these concepts only in relation to the related ideas expressed by the spoken law. Against any natural linguistic logic, they used a keyword to define an instrumental, abstract, immaterial legal reality (rules, rights, duties) and then used compound derivative terms (behaviour in conformity with the rule, behaviour in violation of the rule, exercise of right, performance of duty) to indicate the real historical objects for which the instruments were intended. ${ }^{36}$
\end{abstract}

This passage implies the specificity of normativity (with a paradoxical twist) that initially characterized mute law. Here, a rule is not an abstract, immaterial (and perhaps linguistic) concept that opposes a real fact. Rather, there is a sort of identification between the mute rule and the behavior in compliance with the rule. The mute rule would not exist without the corresponding compliant behavior.

\title{
IV. “Natural Normativity" in Non-Human Animals (Frans de Waal)
}

A second positive answer to the question of whether non-human animals can act in light of rules comes from the research by the American primatologist of Dutch origin Frans de Waal, who dedicated almost thirty years of his research to investigating the morality of non-human primates. ${ }^{37}$ In this research which began with his famous book, Chimpanzee

34. Op. cit., 459-60.

35. Frans B.M. de Waal, Primates and Philosophers: How Morality Evolved (Princeton, NJ: Princeton University Press, 2006), p. 42.

36. Sacco, "Mute Law," 467.

37. Another interesting research on animal morality was conducted by the American psychologist Jonathan Haidt. See J. Haidt, "The Emotional Dog and Its Rational Tail: A Social Intuitionist Approach to Moral Judgment," Psychological Review 108(4) (2001), 814-34; and J. Haidt, "The Moral Emotions," in R.J. Davidson, K.R. Scherer and H.H. Goldsmith (eds.), Handbook of Affective Sciences (Oxford: Oxford University Press, 2003), pp. 852-70. At the heart of Haidt's proposal are the notions of "moral intuition" and "moral emotion." 
Politics. Power and Sex among Apes, published in 1982, de Waal has explicitly addressed the question of whether there are social rules that govern the behavior of non-human primates. ${ }^{38}$ In particular, in a recent work, de Waal claims that there is plenty of evidence to show that animals can implement nomic behaviors: "[d]efining normativity as adherence to an ideal or standard, there is ample evidence that animals treat their social relationships in this manner. In other words, they pursue social values." 39

However, he first considered the question of the normativity of animal behavior with the essay "The Chimpanzee's Sense of Social Regularity and Its Relation to the Human Sense of Justice" which appeared in $1991 .{ }^{40}$ Here he examines the rules that govern faceto-face relationships in primates. This is an important difference in relation to the investigation of animal normativity outlined by Rodolfo Sacco. Unlike Sacco, de Waal does not explore the norms that operate at the level of the social group; rather he predominantly investigates the rules that govern the primates' behavior during face-to-face relations. De Waal calls this "one-on-one normativity" to distinguish it from which we could perhaps call "communal normativity." 41 Moreover, de Waal has repeatedly stated that he is skeptical about the existence of true normativity that is operative among animals at the community level. ${ }^{42} \mathrm{He}$ argues that current ethological knowledge shows little sign of the existence of this second kind of normativity among non-human primates.

De Waal's research (which is in full agreement on this point with what Goodall argues in her essay "Order without Law") is based on the idea that the social world of animals is characterized by a collective order that is expressed in behavioral regularities. Therefore, according to de Waal, animal behavior is to a certain extent scientifically predictable:

All animals conform to social rules. That is, their conduct toward conspecifics is to some degree predictable. The complexity of these rules is inversely related to a species' learning abilities. Fish and insects exhibit a rather limited set of interaction patterns, whereas most mammals

38. Frans B.M. de Waal, Chimpanzee Politics. Power and Sex among Apes (London: Cape, 1982).

39. Frans B.M. de Waal, "Natural Normativity: The 'Is' and 'Ought' of Animal Behavior," Behaviour 151 (2014), 185.

40. Frans B.M. de Waal, "The Chimpanzee's Sense of Social Regularity and Its Relation to the Human Sense of Justice," American Behavioral Scientist 34 (1991), 335-49.

41. de Waal, "Natural Normativity," 197. Interesting examples of one-on-one normativity can be found in Marc Bekoff's essay "Social play behaviour: Cooperation, fairness, trust, and the evolution of morality," Journal of Consciousness Studies 8(2) (2001), 81-90. Here Bekoff examines the notion of "behaving fairly" in play between animals. This is clearly a behavior that is influenced from a normative point of view. In particular, Bekoff notes that at the root of this behavior there must be a tacit agreement between the animals at play, that is, the fact of agreeing to play and consequently behaving "fairly." Here are two examples of "fair behaviour" during the game: "a coyote might not bite her play partner as hard as she can, or she might not play as vigorously as she can" and "a dominant animal might not voluntarily roll-over on his back during fighting, but would do so while playing" (Bekoff, "Social play behaviour," 83). Play is also a way of learning basic rules of one-on-one interaction: for example, "how hard they can bite."

42. See, for example, de Waal, "Chimpanzee's Sense of Social Regularity," 335, and de Waal, "Natural Normativity," 197-200. 
exhibit a wide range of social behaviour with great adaptability to new circumstances. Yet while the behaviour of mammals may be flexible, it is not irregular. For example, females with young respond with either withdrawal or aggression to conspecifics that pose a threat to their offspring. Females may do so in different ways or to a different degree, but protection of offspring is a general rule. ${ }^{43}$

The above quote should not be misunderstood, however. In this passage, de Waal uses the term "social rules" to denote mere behavioral regularities, not actual social rules. Here we need to introduce a conceptual distinction found in de Waal's research on animal normativity, in which he makes use of a rich theoretical toolbox for his investigation of social norms.

Alongside the distinction between the concepts of one-on-one normativity and communal normativity, in considering the role of social regularity in the behavior of chimpanzees de Waal differentiates between two types of rules: "descriptive rules" and "prescriptive rules." $44 \mathrm{He}$ uses the expression "descriptive rules" to refer to behavioral regularities, in other words, "the typical responses to specific situations." As de Waal writes, descriptive rules are less interesting because they lack the "crucial 'ought' quality": "[o]nly animals and humans follow prescriptive rules, rules actively upheld through reward and punishment." 45 For our purposes, the more interesting category is the latter, namely that of "prescriptive rules," which are not "rules to which members of a species merely conform but ones that they have learned to respect because of active reinforcement by others." Taking the example of maternal protection, de Waal writes:

[I]t is easy to see how this response may affect the way in which infants are being treated. Any individual deviating from the mother's norms regarding the treatment of her young will meet with either hostility or retrieval of the offspring. A prescriptive rule is born when members of the group learn to recognize the contingencies between their own and the mother's behaviour and to act in a way that minimises negative consequences. ${ }^{46}$

Clearly, our fundamental epistemic problem lies in the transition from mere observation of descriptive rules (i.e., from the observation of mere behavioral regularities) to the identification of fully prescriptive rules.

Moving on from norms to normativity in his investigation of morality in the animal world, de Waal not only questions the nature and the typology of the norms, but also the very nature of normativity itself, and this reflection highlights an interesting distinction between three forms of animal normativity.

According to the first characterization, normativity consists of "conformity to an ideal or standard." If we conceive normativity in this way, de Waal argues, it is difficult to refute the idea that the behavior of many animals is nomic. As he writes, "[t]hat animal behaviour is not free of normativity (defined as the adherence to an ideal or standard) is hardly in need of argument":

43. de Waal, "Chimpanzee's Sense of Social Regularity," 337.

44. See op. cit. and Frans B.M. de Waal, Good Natured: The Origins of Right and Wrong in Humans and the Other Animals (Cambridge, MA: Harvard University Press, 1996).

45. de Waal, Good Natured, p. 90.

46. de Waal, "Chimpanzee's Sense of Social Regularity," 337-8. 
Take the spider's reaction to a damaged web. If the damage is extensive she will abandon her web, but most of the time she will go into repair mode, bringing the web back to its previous functional state by filling holes or tightening damaged threads by laying new ones [...]. Similarly, disturbing an ant nest or termite hill leads to immediate repair, as does damage to a beaver dam or bird nest. Nature is full of physical structures built by animals guided by a template of how the structure ought to look. ${ }^{47}$

It is obviously possible to describe animal behavior without referring to purposes, intentions and values, but according to de Waal this would lead to the loss of an essential aspect:

Non-human primates, as well as many other animals, strive for specific outcomes. They do so both in relation to physical structures, such as nests and webs, and in relation to social relationships. They actively try to preserve harmony within their social network. They frequently correct deviations from this ideal by, e.g., reconciling after conflict, protesting against unequal divisions, and breaking up fights amongst others. They behave normatively in the sense of correcting, or trying to correct, deviations from an ideal state. They also show emotional self-control and anticipatory conflict resolution in order to prevent such deviations. This makes moving from primate behaviour to human moral norms less of a leap than commonly thought. ${ }^{48}$

By contrast, according to the second characterization, the normativity of animal behavior lies in "conformity with actual social rules" and is inextricably connected with the existence of "normative expectations" (to use the lexicon of Norwegian sociologist Johan Galtung) relating to how the self and others must be treated, or how resources should be shared out. 49

I will describe behaviour in chimpanzees and other primates that seems to reflect a sense of social regularity, that is, a sense of how others should or should not behave. This sense, which may be a precursor of the sense of justice, is defined here as a set of expectations about the way in which oneself (or others) should be treated and how resources should be divided, a deviation from which expectations to one's (or the other's) disadvantage evokes a negative reaction, most commonly protest in subordinate individuals and punishment in dominant individuals. The sense of social regularity is basically egocentric, although the interests of individuals close to the actor, especially kin, may be taken into account, hence the parenthetical inclusion of others in the definition..$^{50}$

From an epistemological point of view, de Waal stresses that there is an obvious problem for ethologists in that (normative) expectations cannot be observed directly, but this does not mean that they do not exist. ${ }^{51}$ Indeed, de Waal recalls that Otto L. Tinklepaugh (in his

47. de Waal, "Natural Normativity," 187. On the architecture of the animal world, see Mike Hansell, Animal Architecture (Oxford: Oxford University Press, 2005).

48. de Waal, "Natural Normativity," 200.

49. On the concept of "normative expectation," see Johan Galtung, "Expectations and interaction processes," Inquiry: An Interdisciplinary Journal of Philosophy 2(1-4) (1959), 213-34.

50. de Waal, "Chimpanzee's Sense of Social Regularity," 336.

51. Op. cit., 337. 
essay "An experimental study of representative factors in monkeys" published in 1928) had already demonstrated that monkeys show surprise and frustration when an event they have been anticipating fails to come about. ${ }^{52}$

Moreover, as we have already noted, another very important element in addition to expectations is reprisal, the harsh reaction that follows any act that deviates from the rules. ${ }^{53}$ For example, in the case of apes (which develop slower than monkeys), de Waal claims that apes up to the age of four can exhibit "bad" behaviors that openly violate the norms of the social hierarchy (for example, jumping on the shoulders of the dominant male to use him as a trampoline, stealing food from the hands of others, or a young ape striking an older member with full force) without incurring any kind of punishment. After this, the reprimand by the alpha male can be dramatic, as in the case of young apes who show excessive interest in menstruating females. ${ }^{54}$ The existence of penalty actions in animal societies was previously described by the British ethologist K.R.L. Hall, whose work focuses specifically on the social life of baboons:

The overall picture of a group organisation in these animals is of a sensitive balancing of forces, the balance being achieved by the social learning of individuals in the group from the time of birth to adulthood, so that infringements of the group norm are rare. When they do occur, they may be severely punished if the victim is caught. ${ }^{55}$

Alongside these two animal characterizations outlined by de Waal (normativity as conformity to a standard and normativity as conformity to rules), we find a third form of normativity that is perhaps subtler and certainly less explored, which consists of the experience of an "ought" feeling, the sensation of having an obligation to behave in a particular way. However, de Waal holds that it is not clear whether animals can really experience these kind of "ought" feelings.

Given the inaccessibility of animal experience, however, the presence of an internalised normativity remains highly speculative. For the moment, this paper makes the weaker claim, that insofar as the "ought" of human morality reflects a preference for certain social outcomes over others, similar preferences seem to guide other animals without necessarily implying that they are guided by the same sense of obligation of how they ought to behave as humans..$^{56}$

In de Waal's view, this is one of the points that could indicate a significant difference between human normativity and animal normativity. The other stark difference concerns

52. Otto L. Tinklepaugh, “An experimental study of representative factors in monkeys," Journal of Comparative Psychology 8(3) (1928), 197-236.

53. On the heuristic power of deviant behavior and sanctions for the study of social norms in the animal world, see Karl Mertens, "On the Identification and Analysis of Social Norms and the Heuristic Relevance of Deviant Behaviour," in Bayertz and Roughley, The Normative Animal?

54. See de Waal, "Natural Normativity," 189-90.

55. K.R.L. Hall, "Aggression in Monkey and Ape Societies," in J. Carthy and F. Ebling (eds.), The Natural History of Aggression (London: Academic Press, 1964), p. 56.

56. de Waal, "Natural Normativity," 187. 
the fact that animal normativity is of a more "concrete" nature than the human equivalent, in that non-human primates "do not seem to extend norms beyond their immediate social environment, and appear unworried about social relationships or situations that they do not directly participate in." 57

Animals are affected by a normativity that pertains exclusively to momentary and current phenomena. It is a normativity in praesentia, insofar as it is relative to a specific, concrete situation, to the relationship between two specific individuals who are facing each other at that particular moment. For example, similarly to the case of mute law theorized by Sacco, the right of property on a certain object materializes in the momentary violent action of defense but is not projected into the future or into relationships with absent subjects. ${ }^{58}$

\section{V. “Naïve Normativity” in Non-Human Animals (Kristin Andrews)}

A third positive answer to the question of whether non-human animals can also act nomically comes from a philosophical reflection on animal normativity, and, in particular, from the recent (and still on-going) research conducted by the Canadian philosopher Kristin Andrews. This research is driven by the intention to remove the anthropocentric lens that frames research on normativity, which is in turn based on the presumption that humans are unique in terms of their normative practices. Starting from a vast corpus of data originating from ethological research, Andrews claims that there is evidence that species other than humans "understand one another through a normative lens that $[\ldots]$ creates expectations that community members strive to live up to." She also asserts that non-human animals can be "sensitive" to normativity, and can therefore implement "normative practices." 59 Specifically, Andrews' investigations concern the normative sensibility and practices that characterize great apes and cetaceans.

According to Andrews, certain primates have the ability to create, follow and violate social norms that relate to loyalty, loss, and cooperation. Moreover, individuals appear to have an "implicit knowledge" of the relative norms, as demonstrated by the reactions to

57. Op. cit., 200.

58. An exception to de Waal's theory could possibly come from the ethological research on revenge, of which he was in fact one of the forerunners. These studies have hypothesized the existence of penalizing behavior within aggressive behavior that is not implemented immediately after the aggressive action that affected the avenging animal. See Frans B.M. de Waal and Lesleigh M. Luttrell, "Mechanisms of social reciprocity in three primate species: Symmetrical relationship characteristics or cognition?," Ethology \& Sociobiology 9 (1988), 101-18; and Filippo Aureli, Roberto Cozzolino, Carla Cordischi and Stefano Scucchi, "Kinoriented redirection among Japanese macaques an expression of a revenge system?," Animal Behaviour 44(2) (1992), 283-91.

59. See Kristin Andrews, "Understanding norms without a theory of mind," Inquiry 52(5) (2009), 433-48, and K. Andrews, "The Folk Psychological Spiral: Explanation, Regulation, and Language,” The Southern Journal of Philosophy 53 (2015) [Spindel Supplement: Alternative Models of the Mind], 51. 
violations thereof. ${ }^{60}$ Many studies have shown that individuals that violate social norms may undergo aggression or ostracism. ${ }^{61}$ Here is a clear example of nomic behavior, that Andrews takes up from Boesch's essay "Cooperative hunting roles among Taïe chimpanzees," describing the rules among chimpanzees for dividing up prey. ${ }^{62}$

[S]ome chimpanzee societies engage in a highly complex cooperative hunting strategy, and have meat-sharing rules corresponding to the individual roles performed by those in the hunting party [...]. Typically, there are four roles that the animals will take when hunting monkeys: driver, chaser, ambusher, and captor. When the prey is spotted, each of the hunters takes on one of these roles, based on their location in relation to the monkey and their anticipation of the monkey's behavior. The hunters have to behave flexibly, for they will change roles as the situation dictates, and fall back to rely on one another if that seems to be the most efficient way to achieve the goal. Each of these roles is quite sophisticated, and it can take the chimpanzees twenty years to become proficient in the more sophisticated hunting roles. Once the hunt is concluded, the meat is divided up between the four hunters. While the age and dominance of each member of the hunting party affects the distribution of meat, the most significant factor determining distribution is the degree of effort. The meat-sharing rules state that the largest share of the meat goes to the animal who did the most to catch the prey. As an implicit rule governing behavior, chimpanzee meat-sharing may be seen as a norm that deals with fair distribution and cooperation, and involves negotiating between one's personal desire for the meat and the more impersonal value associated with fair distribution. ${ }^{63}$

Despite their many parallels, a profound difference between Frans de Waal's research and that of Kristin Andrews clearly emerges from these lines. Unlike de Waal, Andrews is expressly interested in examining "nomic" behavior in animals, whereas she is not concerned with exploring the hypothetical "moral" behavior of non-human animals. She therefore concentrates on "more basic practices" in relation to moral behaviors. The focus of Andrews's research is on animals acting according to social rules, as she herself stresses: "By norms, I am referring to societal rules and expectations; [...] I need not defend the claim that these are, strictly speaking, moral norms, although some of them may be." 64 Moreover, Andrews seems to privilege communal normativity over the oneon-one normativity studied by de Waal.

The idea of "normativity" thus gives rise to a fundamental idea, and, in light of all of this, Andrews has developed her own concept of animal normativity in her subsequent works, a concept she calls "naïve normativity" which, she argues, provides the basis for both social interactions and moral actions.

In elaborating this new notion of normativity, she draws on the theory of "primitive normativity" recently proposed by Hannah Ginsborg in her essay "Primitive

60. Andrews, "Understanding norms," 443-4.

61. For a review of the topic, see Sarah F. Brosnan, "Nonhuman species' reactions to inequity and their implications for fairness," Social Justice Research 19 (2006), 153-85. On ostracism in animal societies, see Gruter, "Ostracism."

62. Christophe Boesch, "Cooperative hunting roles among Taïe chimpanzees," Human Nature 13 (2002), 27-46.

63. Andrews, "Understanding norms," 443-4.

64. Op. cit., 440. See also Vincent, Ring and Andrews, "Normative Practices of Other Animals," and Andrews, "The Folk Psychological Spiral," 60. 
Normativity and Skepticism about Rules." 65 Ginsborg represents primitive normativity as a form of normativity (a sense of "ought") that does not depend on conformity to an antecedently recognized rule, but rather comprises two elements: (i) the mere sensation of the appropriateness (or correctness) of the action being carried out, namely in the sensation of performing an action appropriate to the context, independently of any knowledge of a previous applicable rule to be adhered to; and (ii) being motivated to perform an action by the sensation that it is the right way to act. ${ }^{66}$ Ginsborg also stresses that the sense of appropriateness is derived from the implicit recognition of the rule that is being followed, a rule that is somehow "gathered" by the agent, even if they are not able to formulate it linguistically. ${ }^{67}$ This would then imply a genuinely nomic behavior, even though, as Andrews suggests, it would not presuppose either the ability to articulate this knowledge linguistically or even the necessity of language or metacognitive skills. ${ }^{68}$

Starting from this notion, Andrews develops a theory of "naïve normativity" understood as a cognitive "ability to engage in reasoning about how others should act" 69 or "capacity for ought-thought"70 (the ability to think normatively or deontically), which is a prerequisite of basic normative practices. Andrews considers her notion of "ingenuous normativity" to be a "cultural" version of Ginsborg's primitive normativity. ${ }^{71}$ Indeed, according to Andrews, the concept of ingenuous normativity cannot disregard the identification among members of a group and the desire to imitate their behavior. Furthermore, ingenuous normativity not only allows the behavior of a member of a group to be predicted, it also generates a social pressure gauged to solicit actions compatible with the way the members of the group usually behave.

In Andrews's view, this ability shared by humans and certain animals (such as great apes and cetaceans) presupposes a feeling of belonging to a social group, which leads to ingroup identification and to in-group/out-group discrimination. ${ }^{72}$ Moreover, this in-group identification ensures that certain behaviors are perceived as proper to the given in-group.

In addition, a second important element that characterizes the notion of ingenuous normativity lies in the fact that the sense of oughtness is not based on propositional understanding of rules or even the concept of "ought." Rather, it is the sensation that some things ought to be done a certain way by certain individuals. ${ }^{73}$

65. Hannah Ginsborg, "Primitive Normativity and Skepticism about Rules," The Journal of Philosophy 108(5) (2011), 227-54.

66. Op. cit., 233-5.

67. Op. cit., 238.

68. Kristin Andrews, "Naïve normativity," September 30, 2014. [http://philosophyofbrains. com/2014/09/30/naive-normativity.aspx] (accessed August 21, 2018).

69. Op. cit.

70. Vincent, Ring and Andrews, "Normative Practices of Other Animals."

71. Andrews, "Folk Psychological Spiral," 60.

72. Kristin Andrews, "Pluralistic Folk Psychology in Humans and Other Apes," in Julian Kiverstein (ed.), The Routledge Handbook of the Philosophy of the Social Mind (Abingdon: Routledge, 2016), p. 126.

73. Andrews, "Folk Psychological Spiral," 55. 
The concept of "expectation" also seems to play an important role in the definition of "ingenuous normativity." According to Andrews, there is some evidence that chimpanzees expect others to act in compliance with certain social rules on grooming or the treatment of infants, although this is still very much an open question. ${ }^{74}$

Naïve normativity - that lens through which we see others as in-group members we're motivated to model, or as out-group members we want to distance ourselves from - is something we have evidence for in chimpanzees. Chimpanzees also appear to make generalisations about other individuals, expecting that another will act in the future as he acted in the past. They also expect individuals to act differently in different situations, and to act according to their dominance role. ${ }^{75}$

In a (forthcoming) essay written together with Sarah Vincent and Rebecca Ring, Andrews also considers cetaceans in addition to great apes, claiming that there is clear proof of normativity in various cetaceous species. Significant studies have been carried out on cetaceans in the past fifty years, although there is still much less available data than for great apes. As Vincent, Ring and Andrews write: "Cetaceans are marine mammals, including all whales, dolphins, and porpoises. They live entirely in aquatic environments, primarily in a world of sound, where some perceive and relate to their world using echolocation or sonar - a sensory system that we great apes do not share. Despite these differences, we argue that cetaceans share with the great apes the capacity for ought-thought."76

One very interesting phenomenon in terms of this capacity to have deontic thoughts is that of the absence of "incestuous" behaviors among orcas (Orcinus orca) in one of the three populations of the north-western Pacific. On the basis of studies conducted by the ethologist Lance Godfrey Barrett-Lennard, which have shown that coupling among orcas always takes place between reproducers that do not belong to the same line of matrilineal progeny, Vincent, Ring and Andrews hypothesize the existence of a social taboo of incest, given the incredible success of the mechanism for aversion toward incest within a social group formed of members that share a particular "dialect" (i.e., a given set of vocal calls), a diet, and given norms concerning foraging. ${ }^{77}$

74. Recently, the existence of normative expectations in bonobos (Pan paniscus) and the vocal protests against the violation of these kinds of expectations have been analyzed by Zanna Clay, Lucie Ravaux, Frans B.M. de Waal and Klaus Zuberbühler in their essay "Bonobos (Pan paniscus) vocally protest against violations of social expectations," Journal of Comparative Psychology 130(1) (2016), 44-54. According to them ("Bonobos," 50), "great apes mark violations of social expectations vocally in the biologically relevant context of aggressive conflicts." Particularly, "bonobos appear sensitive to perceived violations of self-oriented social expectation in the context of aggressive conflicts and publicly broadcast their protest through the use of individually distinctive victim screams."

75. Andrews, "Pluralistic Folk Psychology," 133.

76. Vincent, Ring and Andrews, "Normative Practices of Other Animals."

77. See Lance Godfrey Barrett-Lennard, "Population structure and mating patterns of killer whales (Orcinus orca) as revealed by DNA analysis," unpublished $\mathrm{PhD}$ thesis, University of British Columbia, 2000. 


\section{Toward an Ethology of Normativity}

The aim of this essay is to highlight the relevance of ethological research for the philosophical investigation of norms and normativity, and to inaugurate a new field of studies that could be called the "ethology of normativity."78 My hope is that the study of normative phenomena in the animal world can become an important tool for expanding knowledge of human normativity.

Over the past thirty years, ethological research has only investigated normativity in the animal world tangentially, and has considered the hypothetical "moral" or "legal" behavior of non-human animals above all. What I propose is to focus attention on specifically "nomic" behavior on the part of animals and their hypothetical ability to act in light of rules, which seems to be a precondition for moral and legal behaviors. In my opinion, these studies into the ethology of normativity can be heuristically fruitful for social philosophy, in that they can shed new light on the nature of normativity, starting from the analysis of phenomena that have long been overlooked by studies on norms. It is to Kristin Andrews's great credit that she has brought attention to these strange normative phenomena in the animal world.

In this essay, I have tried to indicate a starting point for this study of animal normativity, presenting and reconstructing three of the most important voices supporting the thesis that non-human animals are able to perform nomic behaviors. Alongside the positions I have described, there are of course academics who are more skeptical of the existence of norms in the animal world. Laura Schlingloff and Richard Moore, for example, assert that on the basis of the available data it is too early to conclude whether chimpanzees understand and follow norms in either conventional or moral domains. ${ }^{79}$ This skepticism is also partially shared by ethologists (such as de Waal) who use the categories of "norm," "normativity" and "ought" abundantly in their research. Obviously, the debate is still open and research in this field is likely only at in its early stages.

However, there is a fixed point from which new research can begin, namely recognition of the existence of a social order in the animal world. There are behavioral regularities that cannot be doubted, as de Waal often highlights and as Goodall (in the essay "Law without Order") previously claimed. Indeed, the existence of these behavior regularities has been acknowledged since the start of the last century. For example, we could think of the "pecking order" or "peck order" (the ranking of access to food) among the hens (Gallus domesticus) in a henhouse, which was described for the first time by the Norwegian ethologist Thorleif Schjelderup-Ebbe in $1921 .{ }^{80}$ Of course, the fundamental epistemological problem concerning these ethological studies of normativity lies in verifying whether there is an actual norm underpinning these social regularities. In other words, the question remains as to whether it is possible to start with a simple behavioral regularity (pecking order in a

78. On the importance of ethological research for investigating the evolution of law and for the social sciences, see Hayek, Law, Legislation and Liberty, p. 74.

79. Laura Schlingloff and Richard Moore, "Do Chimpanzees Conform to Cultural Norms?" in Kristin Andrews and Jacob Beck (eds.), The Routledge Handbook to the Philosophy of Animal Mind (Abingdon: Routledge, 2018), pp. 381-9.

80. Thorleif Schjelderup-Ebbe, "Gallus domesticus in seinem täglichen Leben," unpublished PhD thesis, University of Greifswald, 1921. 
henhouse, for example) in order to confirm the existence of a complete "deontology of the henhouse" (to use Searle's lexicon) that determines this regularity. To put it yet another way, can we hypothesize the existence of individual pecking rights for the various hens in a henhouse? If there are such rights, then there would be in the henhouse institutional phenomena akin to our queues at the post office.

As de Waal writes, of course we cannot use language to collect information on these normative phenomena with animals, as is the case in anthropology. (Moreover this problem also remains in relation to humans with regard to pre-linguistic infants. ${ }^{81}$ ) The epistemological problem therefore lies in the identification of possible indicators of normativity. However, ethologists have described interesting phenomena that seem to support the notion that non-human animals actually can have a nomic capacity. Here are two taken from de Waal's research.

One phenomenon that supports the thesis of the existence of actual norms in the animal world is derived from an ethological observation of the behavior of adults toward young animals. Young infants seem to live "above the law":

\begin{abstract}
Monkeys do not come into this world with social rules imprinted in their heads. Neonates enjoy a certain Narrenfreiheit: like jesters at the court, they live above the law. Young infants may bump into high-ranking adults or approach food that others are interested in without being threatened or chased away as any juvenile would. In our studies of rhesus monkeys, for example, we discovered that infants occupy a better position than their mothers in the group's drinking order because they are allowed to approach the water basin and drink side by side with dominants who do not tolerate the mothers. ${ }^{82}$
\end{abstract}

A social regularity is broken here, although this exception does not appear to reveal the absence of social norms, but rather the recognition of the particular status that young animals have within the community, which allows them to live above the law, that is, to break the rules without being subject to any sanctions. ${ }^{83}$ In this case, there is a sort of diffraction of adult behavior from regular behavior, which is only explained in light of a normative principle of tolerance toward young infants.

81. In recent years, social psychologists have begun exploring nomic behavior in pre-school age children (specifically, 2- and 3-year-old children) in light of research into social ontology, and to investigate their ability to act in light of constitutive rules. See Hannes Rakoczy, Felix Warneken and Michael Tomasello, "The sources of normativity: Young children's awareness of the normative structure of games," Developmental Psychology 44(3) (2008), 875-81; Emily Wyman, Hannes Rakoczy and Michael Tomasello, "Normativity and context in young children's pretend play," Cognitive Development 24 (2009), 146-55; Marco F.H. Schmidt and Michael Tomasello, "Young Children Enforce Social Norms," Current Directions in Psychological Science 21(4) (2012), 232-6; and Hannes Rakoczy and Marco F.H. Schmidt, "The early ontogeny of social norms," Child Development Perspectives 7(1) (2013), 17-21. It would be interesting to also extend the research into nomic behavior to pre-linguistic children.

82. de Waal, Good Natured, p. 112.

83. In this regard, see the interesting case of the Japanese macaque Wania-6672 described by Linda M. Fedigan and Laurence Fedigan, "The social development of a handicapped infant in a free-living troop of Japanese monkeys," in Frank E. Poirier and Suzanne ChevalierSkolnikoff (eds.), Primate Biosocial Development: Biological, Social and Ecological Determinants (New York: Garland Press, 1977), pp. 205-22. 
A second phenomenon (also described by de Waal) that tends to support belief in the nomic capacity of non-human animals relates to the behavior of a group of chimpanzees in captivity, which seems to originate from the recognition of norms imposed from above, in this instance not on the part of the dominant animals, but rather the keepers of the animals in captivity:

The tendency to enforce orderly conduct is so strong that human custodians of captive primate colonies can take advantage of it. In Arnhem, chimpanzees assist their caretakers in getting every colony member to enter the building in the evening. The human-imposed rule is simply that none of the apes will receive food until all of them have moved from the island into their sleeping quarters. As a result, latecomers meet with a great deal of hostility from the hungry colony. On one occasion, when two adolescent females stayed out for hours on the island, not even their isolation in a separate night cage could prevent punishment. The account was squared the following morning on the island, where the colony vented its frustration about the delayed meal. ${ }^{84}$

Undoubtedly, the morning after's violent behavior (aimed at punishing the two females guilty of not returning from the island with the others) is nomic behavior that arises from the recognition of the rule that no apes will receive food until everyone is in their sleeping quarters. Here the apes act in light of a rule, without acting according to this rule.

\section{Animal Normativity: a Kind of Normativity without Norms and Language?}

In conclusion, we could ask ourselves: why study the nomic behavior of non-human animals? What can the ethological study of norms contribute to the study of human normativity?

This research can certainly enrich our image of normativity, providing new categories of investigation and opening up new research directions. I shall consider two at least.

One initial research direction concerns the hypothesis of "pre-linguistic normativity" or "normativity without language." In other words, the ethological study of normativity forces us to reflect on the hypothetical existence of social normativity outside a linguistic framework, as well as on the possibility of normative thought in the absence of language (or, more precisely, on the possibility of a "non-propositional deontic thought"), if it is true, as Andrews suggests, that non-human primates also lead a "life of oughts." 85

84. de Waal, "Chimpanzee's Sense of Social Regularity," 341.

85. Andrews, "Folk Psychological Spiral," 60. The hypothesis of "pre-linguistic normativity" presupposes the image of non-human animals as beings who lack language. Actually, this is where the ethological survey of normativity meets another fascinating investigation of the animal world: the investigation of the linguistic ability of non-human animals. Do some animals have their own language (with their own semantics and their own syntax)? On this subject, see R.M. Seyfarth, D.L. Cheney and P. Marler, "Monkey responses to three different alarm calls: Evidence of predator classification and semantic communication," Science 210 (1980), 801-3; Karim Ouattara, Alban Lemasson and Klaus Zuberbühler, "Campbell's monkeys concatenate vocalizations into context-specific call sequences," Proceedings of the National Academy of Sciences of the United States of America 106(51) (2009), 22026-31; 
An important contribution to the investigation of pre-linguistic normativity comes from the research of José Luis Bermúdez concerning thoughts without language. In particular, he conceives of animals as genuine thinkers, despite their not being linguistic creatures. ${ }^{86}$ According to Bermúdez, we come up against a form of animal thought every time we find ourselves faced with an animal behavior that cannot only be explained in terms of classical conditioning (i.e., in terms of animal training or Pavlovian conditioning) or instinct and innate releasing mechanisms. ${ }^{87}$ Starting from the notion of proto-thoughts proposed by Michael Dummett, ${ }^{88}$ Bermúdez distinguishes between different types of thoughts without language. ${ }^{89}$ The following theory can be posited on the basis of these studies: non-human animals are genuine thinkers that can have authentic deontic thoughts. This hypothesis seems to be fully compatible with the theory of naïve normativity among non-human animals proposed by Andrews. ${ }^{90}$

Another direction of inquiry relates to the idea of "normativity without norms." In particular, as we have seen, the research of Frans de Waal and Kristin Andrews has made interesting contributions to the philosophy of normativity by suggesting the idea of a "proto-normativity" that is not characterized in terms of actual norms. Andrews defines her notion of "ingenuous normativity" as a form that consists of the mere sensation of the appropriateness (or correctness) of the action that is being carried out, namely the sensation of carrying out an action appropriate to the context, independently of any knowledge of a prior rule to follow, and with the motivation to continue the action with the sensation that it is the right way to act. In parallel to this, when he reflects on the behavior of "architect" animals, such as spiders repairing cobwebs that are not irreparably damaged or ants repairing an anthill, de Waal hypothesizes the existence of proto-normativity that consists of conformity to an ideal or a

Klaus Zuberbühler, "Linguistic capacity of non-human animals," WIREs Cognitive Science 6 (2015), 313-21. On the strange chemical communication in ants, see Duncan E. Jackson and Francis L.W. Ratnieks, "Communication in ants," Current Biology 16(15) (2006), R570-4.

86. On forms of non-linguistic animal thought, see Mariela Aguilera, "Animales sin lenguaje en el espacio de los conceptos," Teorema: Revista Internacional de Filosofia 29(2) (2010), 25-38, and Laura Danón, "Undetachable Concepts in Non-Human Animals," Philosophies 3(2) (2018), 14.

87. For a classic study of instinct, see Niko Tinbergen, The Study of Instinct (Oxford: Clarendon, 1951).

88. Michael Dummett, The Origins of Analytical Philosophy (London: Duckworth, 1993), pp. $121-6$.

89. See José Luis Bermúdez, "Ascribing Thoughts to Non-Linguistic Creatures," Facta Philosophica 5 (2003), 313-34, J.L. Bermúdez, Thinking Without Words (Oxford: Oxford University Press, 2003), and J.L. Bermúdez, "Thinking Without Words: An Overview for Animal Ethics," Journal of Ethics 11 (2007), 319-35.

90. Language is undoubtedly an important tool for maintaining, transmitting and increasing compliance with the rules; for example, it seems to be a necessary tool to recruit the support of others in the maintenance of the norms (Brosnan, "Property in non-human primates," 20). This does not mean that the linguistic framework is an indispensable condition for the existence or the genesis of the norm. 
standard: "[n]ature is full of physical structures built by animals guided by a template of how the structure ought to look." 91

Here we find ourselves facing a normative world with an apparently paradoxical aspect, in that this is apparently a world without norms and lacking a linguistic framework. But how is it possible for normativity to exist in the absence of norms and language? This opens up the possibility of new research into a normative world that is still largely unknown, and which deserves to be carefully explored. ${ }^{92}$

91. de Waal, "Natural Normativity," 187.

92. In this regard, moreover, it is important to note that investigations on animal normativity have until now been principally focused, as we have seen, on mammals, and in particular on primates and cetaceans. An important hope for future research on the ethology of normativity is that this research also extends to the remaining animal world, and therefore also to the invertebrate world. As an example, it would be particularly interesting to investigate if there are traces of normativity in the life of insects who live in societies such as ants, termites, bees and wasps. In 1928 William Morton Wheeler publishes his book The Social Insects: Their Origin and Evolution (New York: Harcourt, Brace and Company; Kegan Paul, Trench, Trubner \& Co., 1928) and on social insects also writes Edward O. Wilson in his book The Insect Societies (Cambridge, MA: Belknap Press of Harvard University Press, 1971). But, we could ask ourselves: are there also "nomic insects," i.e. insects able to act in light of norms? Moreover, in the future agenda of the "ethology of normativity," it could be interesting to investigate the biological, social and environmental conditions that make normativity possible in the animal kingdom, along with the borders of the normative sphere in the animal world. 